\title{
Interpretation of needle biopsies of the kidney for investigation of renal masses
}

\author{
Benoît Lhermitte • Laurence de Leval
}

Received: 1 February 2012 /Revised: 17 April 2012 / Accepted: 18 May 2012 / Published online: 8 June 2012

(C) Springer-Verlag 2012

\begin{abstract}
The development of new therapeutic options for renal tumors has lead to the need of a pretherapeutic diagnosis for an increasing proportion of patients presenting with a renal mass. This need is particularly important for a small, incidentally discovered renal mass (less than $4 \mathrm{~cm}$ ) as it can be a benign lesion in a significant percentage of cases. Recent studies have shown that needle biopsy is an accurate and safe method allowing for a precise histopathological diagnosis of the mass in most cases. The aims of the biopsy are (1) to assess the benign or malignant nature of the lesion, (2) to assess the primary or secondary nature of the lesion, and (3), in case of a primary malignancy, to determine histological prognostic factors, such as the tumor type. This review, based on the most recent literature and our own experience, is intended to provide a practical approach to the diagnosis, relying on appropriate morphologic assessment and the use of immunohistochemistry.
\end{abstract}

Keywords Kidney · Tumor · Core biopsy · Renal cell carcinoma $\cdot$ Immunohistochemistry

\section{Introduction}

In the past, complete surgical resection (radical nephrectomy) without preoperative histological assessment has long been considered the gold standard for the management of renal masses, as indeed the majority of solid renal tumors are malignant primaries for which surgical management allows

B. Lhermitte $(\bowtie) \cdot$ L. de Leval

University Institute of Pathology,

Centre Hospitalier Universitaire Vaudois (CHUV),

25 rue du Bugnon,

1011, Lausanne, Switzerland

e-mail: benoit.lhermitte@chuv.ch optimal staging and treatment. In that context, core needle biopsies were mostly restricted to situations where the indication of surgery was questionable, i.e., in cases of high suspicion of a benign tumor, metastasis, lymphoma, or abscess [1]. Other factors reported to compound preoperative biopsies included an overestimated risk of noncontributive samples, tumor dissemination along the needle track, and hemorrhagic complications [2].

For the past few years, the number of biopsies for renal masses has virtually exploded. The increased use of crosssectional imaging for other pathologies has lead to the discovery of renal masses, especially of small size, without radiological criteria allowing to determine the nature of the tumor. Nowadays, more than half of all renal tumors are incidentally detected [3]. Moreover, a significant minority (between 15 and $35 \%$ ) of these small renal masses, by definition less than $4 \mathrm{~cm}$, consist of benign lesions which do not require surgical removal [4-7]. At the same time, new therapeutic options including partial nephrectomy, imaging-guided ablative therapy (using radiofrequency ablation, high intensity focused ultrasound, or cryotherapy), active surveillance, or systemic neoadjuvant therapy have emerged for the treatment of renal cell carcinoma $[8,9]$. In these cases (with the exception of partial nephrectomy), these new therapeutic options require pretherapeutic pathological diagnosis. Moreover, the diagnostic accuracy of the biopsy has increased in the last decade [10], as a result of both the improvement in biopsy techniques and the development of immunohistochemistry panels allowing the identification of almost all tumor subtypes and the newly described entities.

There are currently numerous conditions for which the indication of a biopsy can be discussed: (1) the discovery of a small renal mass because it can correspond to a benign lesion for which a partial or radical nephrectomy would not 
be required; (2) in metastatic patients eligible for a systemic therapy with no previous pathology documentation, in order to select therapy by classifying the tumor; (3) a previous history of extrarenal malignancy raising the differential diagnosis of a metastasis or when suspecting lymphoma; (4) a mass associated with a febrile urinary tract infection, in this situation the differential diagnosis includes renal abscess or an inflammatory pseudotumor such as xanthogranulomatous pyelonephritis

Therefore, the aim of a pretherapeutic biopsy is to determine (1) the benign or malignant nature of the lesion, (2) the primary or secondary nature of a malignant lesion, and (3) the tumor type. Lesions that are mostly cystic are currently not an indication for pretherapeutic biopsy because of the difficulty to obtain representative samples of the lesion. The prognosis of cystic lesions can be determined to some extent by appropriate imaging modalities (mainly ultrasound, CT scan, and MRI) using Bosniak's classification [11].

This review is intended to provide a practical approach to the diagnosis of renal core biopsies performed for investigating kidney masses. It is based on the most recent literature concerning the subject and on our own experience.

\section{Technical considerations and diagnostic accuracy}

Biopsies are generally performed by the radiologist under US or helical CT guidance, with the patient in prone position under local anesthesia. CT is performed immediately after needle removal to exclude postbiopsy complications. The recommendation is to use 18-gauge $(\mathrm{G})$ needles (yielding $1.7 \times 0.1-\mathrm{cm}$ cores) and to obtain at least two cores in the periphery of the tumor and in nonnecrotic areas [12]. In a prospective ex vivo study conducted on nephrectomy specimens, aimed to compare the yield of 14-, 18-, and 20-G core needle biopsies, Breda et al. [13] found that three biopsies with 14- and 18-G needles allowed to obtain an adequate diagnosis of solid renal masses in 94 and $97 \%$ of the cases, respectively, while the yield of $20-\mathrm{G}$ needles was significantly inferior $(81 \%)$. Although fine needle aspiration is not the topic of this review, it is worth mentioning that in some centers, smear preparations are examined extemporaneously to verify the adequacy of the sample. Others use it as a diagnostic tool, with an accuracy close to that of needle biopsies, especially in conjunction with immunocytology [16].

The samples are fixed in formalin and submitted as one core per cassette for standard processing and paraffin embedding. In our institution, sections from three levels are stained with hematoxylin and eosin for histopathological evaluation, and four additional sections per level are kept unstained for special stains and/or immunohistochemistry.
When an adequate sample is obtained, the ability to distinguish benign from malignant lesions is excellent and almost reaches $100 \%$ of the cases. Indeed, in an in vivo study, all oncocytomas were well identified [14]. The ability to determine the histological subtype of renal cell carcinoma (RCC) is excellent, especially when adding adequate immunostain with an accuracy of $90 \%$ overall and $99 \%$ among the four most common subtypes [15].

\section{Interpretation}

Renal cell tumors are currently classified according to the World Health Organization (WHO) system which defines tumor entities based on their pathological features, clinical behavior, and genetic alterations (Table 1) [17]. The histopathological diagnosis primarily relies on the examination of routinely stained sections, by taking into account (1) the cytologic features of the tumor cells (i.e., clear, eosinophilic, chromophobic, oncocytic, spindle cells), and (2) the tumor architecture (i.e., solid, acinar, papillary). Assessment of the growth pattern and associated stroma may be of interest for the identification of some renal cell tumor entities and also in the differential diagnosis with nonrenal cell tumors.

\section{Clear cell tumors}

\section{Clear cell renal cell carcinoma}

Clear cell renal cell carcinoma (CCRCC), by far the commonest malignant renal epithelial neoplasm, represents approximately $60 \%$ of renal cortical tumors. Importantly, however, all clear cell lesions are not clear cell renal cell carcinomas, and clear cell renal cell carcinoma is not in fact always composed of clear cells, a reason why some authors advocate the designation "conventional" renal cell carcinoma. Nevertheless, the recommended nomenclature according to the WHO classification remains "clear cell" renal cell carcinoma [17].

In typical cases, the biopsy shows a proliferation of clear cells, possibly admixed with an eosinophilic granular cell component, with a solid or acinar architecture. A prominent delicate and branching vascularization network is characteristic and almost always observed. Secondary changes such as focal fibrosis or hyalinization, geographic necrosis, and focal hemorrhage are frequent. When typical features are observed, the diagnosis is straightforward by morphology and additional ancillary techniques are usually not necessary (Fig. 1). When facing unusual morphology (predominantly granular eosinophilic component or predominantly papillary architecture), immunohistochemistry is helpful to confirm the diagnosis. 
Table 1 Classification of renal cell tumors (adapted from the WHO histological classification of tumors of the kidney, 2004)

Renal cell tumors

Clear cell renal cell carcinoma

Multilocular clear cell renal cell carcinoma

Papillary renal cell carcinoma

Type I

Type II

Chromophobe renal cell carcinoma

Carcinoma of the collecting ducts of Bellini

Renal medullary carcinoma

Xp11 translocation carcinomas

Carcinoma associated with neuroblastoma

Mucinous tubular and spindle cell carcinoma

Renal cell carcinoma, unclassified

Papillary adenoma ${ }^{\mathrm{a}}$

Oncocytoma $^{\mathrm{a}}$

Tumors recently described, not yet listed in the WHO classification

Clear cell papillary renal cell carcinoma

Clear cell carcinoma with leiomyomatous stroma

Oncocytic type papillary carcinoma

Metanephric tumors

Nephroblastic tumors

Mesenchymal tumors

Mixed mesenchymal and epithelial tumors

Neuroendocrine tumors

Hematopoietic and lymphoid tumors

Germ cell tumors

Metastatic tumors

${ }^{\mathrm{a}}$ Benign lesions
CCRCC expresses pan-cytokeratins (for example those recognized by the AE1/AE3 cocktail), epithelial membrane antigen (EMA), vimentin, and CD10 in a membranous distribution. Alpha-methyl CoA racemase (AMACR) expression is detected in up to $68 \%$ but usually more focally than in papillary carcinoma. Cytokeratin 7 (CK7) expression is weak and focal. Less than $10 \%$ of the cases show focal positivity for CD117 while the majority of cases are negative. HMB-45 is negative. Antibodies raised against carbonic anhydrase IX (CA-IX), a membranous enzyme acting to regulate both intracellular and extracellular $\mathrm{pH}$ and whose expression is induced by hypoxie, have been recently characterized and found of interest for diagnostic purposes. The majority $(>85 \%)$ of CCRCC strongly express CA-IX $[18,19]$. Importantly, only a membranous pattern is characteristic for clear cell RCC, while cytoplasmic staining is not specific and often observed focally with preferential distribution around necrotic areas in other nonclear cell renal cell neoplasms.

Nuclear grading as per the Fuhrman grading system should be assigned because it is one of the most important prognostic factors in organ-confined carcinoma [20] and because some authors advocate that in elderly and unfit patients, low-grade carcinoma can be initially observed or ablated rather than operated on, while the former treatments are not appropriate for high-grade RCC [7]. However, the concordance is low (less than $50 \%$ ) between the grades assessed on paired biopsies and surgical specimens, reflecting intratumor heterogeneity [21]. Alternatively, several authors have advocated to combine lower grades (1 and 2) and higher grades ( 3 and 4 ) into a two-tier grading system, which has been shown to reduce the discrepancies between pre- and postsurgical grade assessments [21].
Fig. 1 Core biopsy of a clear cell RCC. Low magnification shows a solid epithelial proliferation (a, hematoxylin and eosin, $\times 2$ ). Higher magnification shows a proliferation of large polygonal cells with clear or finely granular cytoplasm, with round hyperchromatic nuclei (b, hematoxylin and eosin, original magnification $\times 12$ ). In such a case, no ancillary techniques are necessary to confirm the diagnosis

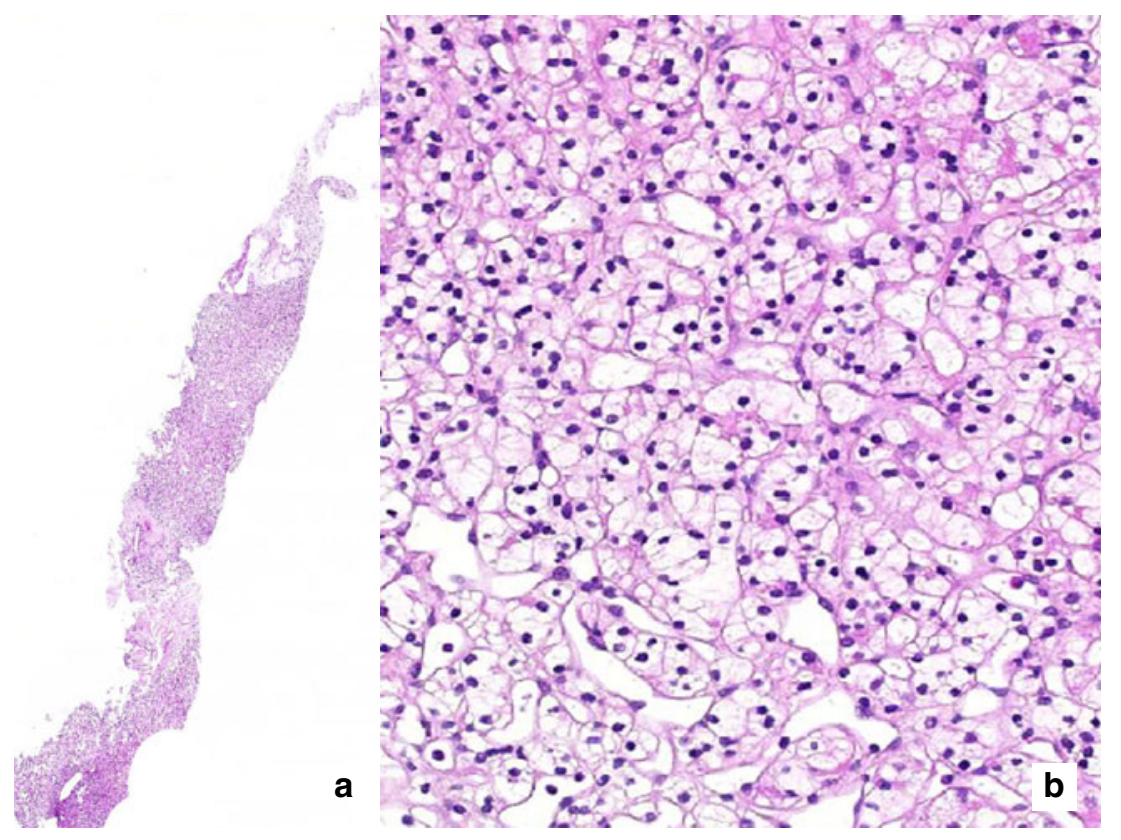




\section{Differential diagnosis}

Clear cell RCC can be confused with a variety of other benign or malignant lesions composed of clear cells (Table 2) [22]. In case of diagnostic problems, immunohistochemistry is a helpful adjunct to careful morphologic evaluation to distinguish between the several diagnostic possibilities (Table 3).

Chromophobe renal cell carcinoma Chromophobe carcinoma is generally composed of an admixture of clear and eosinophilic cells. The cellular contours are sharply delineated with thick membranes accounting for a pseudovegetal aspect. In the clear cells, the nuclei are characteristically wrinkled. Vascularization is less prominent than in CCRCC. The immunohistochemical profile differs from that of CCRCC since chromophobe carcinoma usually does not diffusely express vimentin, CD10, or CA-IX, while conversely CK7 and CD117 are both diffusely expressed.

Clear cell papillary renal cell carcinoma Clear cell papillary renal cell carcinoma, first described in the setting of end-stage kidney diseases, may also occur in the absence of impaired renal function. The few cases with documented clinical follow-up suggest an indolent course. These tumors are usually well circumscribed, encapsulated, and unilateral and measure less than $5 \mathrm{~cm}$. In typical cases, there is a delicate papillary architecture with thin fibrovascular septa lined by a single layer of clear cell. The nuclei, generally relatively bland, are arranged in a linear fashion, centrally, or in the upper pole of the cytoplasm. Purely solid forms do exist as well, with a cord-like or trabeculated pattern, reminiscent of that of sex-cord neoplasms. The immunohistochemical profile is quite characteristic, and the distinguishing features from CCRCC are a strong and diffuse CK7 expression and usual negativity for CD10 [23, 24].

Leiomyomatous renal cell carcinoma Recently, a few cases of renal cell carcinoma with angioleiomyoma-like stroma have been described $[24,25]$. These tumors which appear to run an indolent clinical course are composed of nests, cords,

Table 2 Differential diagnosis of clear cell renal cell carcinoma

Malignant neoplasms

Chromophobe renal cell carcinoma

Clear cell papillary renal cell carcinoma

Clear cell carcinoma with leiomyomatous component

Translocation renal cell carcinoma

Benign lesions

Angiomyolipoma

Histiocytic infiltrates

Adrenocortical tissue and sheets of epithelial clear cells, with low nuclear grade. This epithelial proliferation is dissociated by a stroma featuring mature smooth muscle appearance. The differential diagnosis includes not only CCRCC with fibrohyalinized stroma but also angiomyolipoma and sarcomatoid CCRCC with sarcomatoid component. Unlike CCRCC, the epithelial component of leiomyomatous RCC expresses CK7 and high molecular weight $\mathrm{CK}$, and the stroma shows smooth muscle cell differentiation evidenced by positivity for smooth muscle actin and desmin. Leiomyomatous RCC is negative for melanocytic markers, at variance with angiomyolipoma, and the absence of significant atypia in the stromal component distinguishes it from sarcomatoid carcinoma (Fig. 2).

Translocation-associated renal carcinomas The presence of a mixed alveolar/papillary architecture, an admixture of large clear and eosinophilic cells, and calcifications, especially in a young patient, are features suggestive for a translocation carcinoma. Translocation carcinomas are commonly negative for all epithelial markers, although focal positivity may be observed, especially for EMA. CA-IX, CD10, and vimentin can be expressed, like AMACR, Melan-A, and human melanoma black-45 (HMB45). As discussed below, the diagnosis can be immunohistochemically proven by the nuclear positivity of transcription factor E3 (TFE3) or transcription factor EB (TFEB) or by fluorescence in situ hybridization (FISH) assays [26].

Angiomyolipoma with epithelioid component Angiomyolipomas are composed of variable combinations of spindle or epithelioid smooth muscle cells sometimes with clear cytoplasm, adipose tissue, and abnormal thickwalled blood vessels. In the presence of abnormal vessels or fat, the diagnosis is usually straightforward but in the presence of a fat-poor lesion with prominent epithelioid clear cell component; it can be confused with clear cell RCC. Immunohistochemistry is useful in this setting since the epithelioid cells of angiomyolipoma do not express any epithelial markers, CA-IX, CD10, or AMACR, while smooth muscle actin, desmin, HMB45, and Melan-A will be at least focally positive.

Histiocytic infiltrates Inflammatory lesions or pseudotumors with a high macrophage content can be present on biopsies as clear cell-rich lesions, which may be mistaken as CCRCC. Careful evaluation of the cytologic features will show xanthomatous rather than granular cytoplasm and consistently low-grade nuclear features. Another hint is the frequent admixture of other inflammatory cells and the presence of preserved normal or atrophic renal structures, while conversely carcinoma infiltrates in a pushing and destructive manner. In 
Table 3 Immunohistochemistry for the differential diagnosis of RCC with clear cell features

\begin{tabular}{|c|c|c|c|c|c|c|c|}
\hline & VIM & PanCK & CK7 & CA-IX & CD10 & AMACR & CD117 \\
\hline Clear cell RCC & ++ & + & $-1+$ & ++ & ++ & $+/-$ or - & - \\
\hline Chromophobe RCC & - & ++ & ++ or - & - & - & - & ++ \\
\hline Translocation RCC & ++ & - & - & - & $-1+$ & $+/-$ or - & - \\
\hline Leiomyomatous RCC & ++ & ++ & ++ & ND & ND & ND & ND \\
\hline Clear cell papillary RCC & ++ & ++ & ++ & ND & - & ND & - \\
\hline
\end{tabular}

$N D$ not determined, $R C C$ renal cell carcinoma, VIM vimentin, ++ strong positivity in $>75 \%$ of tumor cells, + moderate positivity in $>75 \%$ of tumor cells, $+/-$ positivity in $50-75 \%$ of tumor cells, $-/+$ positivity in $<50 \%$ of tumor cells, - absence of significant expression

cases of doubt, a limited immunohistochemistry panel with antibodies directed against CD68 and cytokeratins can solve the differential diagnosis (Fig. 3).

Adrenocortical tissue Adrenocortical tissue-either normal or neoplastic and benign or malignant—may be misinterpreted as CCRCC. Biopsy sampling of adrenocortical tissue is more likely to occur when dealing with an upper pole lesion, but one has to be aware of the possibility of renal-adrenal fusion or ectopic adrenal tissue as well. Compared to CCRCC, adrenocortical cells have a more granular cytoplasm and are arranged in a trabecular or nested rather than acinar pattern. Upon immunostaining, adrenocortical tissue lacks expression of EMA or CA-IX and conversely is positive for inhibin, calretinin, synaptophysin, and Melan-A. In a minority of cases, CKAE1-AE3 and CD10 may be positive [22, 27].
Fig. 2 Core biopsy of a leiomyomatous RCC showing a tubuloacinar clear cell epithelial component admixed with a leiomyomatous component (a, hematoxylin and eosin, original magnification $\times 20$ ) . Intense and diffuse expression of CK7 in the epithelial component (b, immunoperoxidase, $\times 10$ ). Intense expression of actin in the leiomyomatous component (c, immunoperoxidase, $\times 10$ )

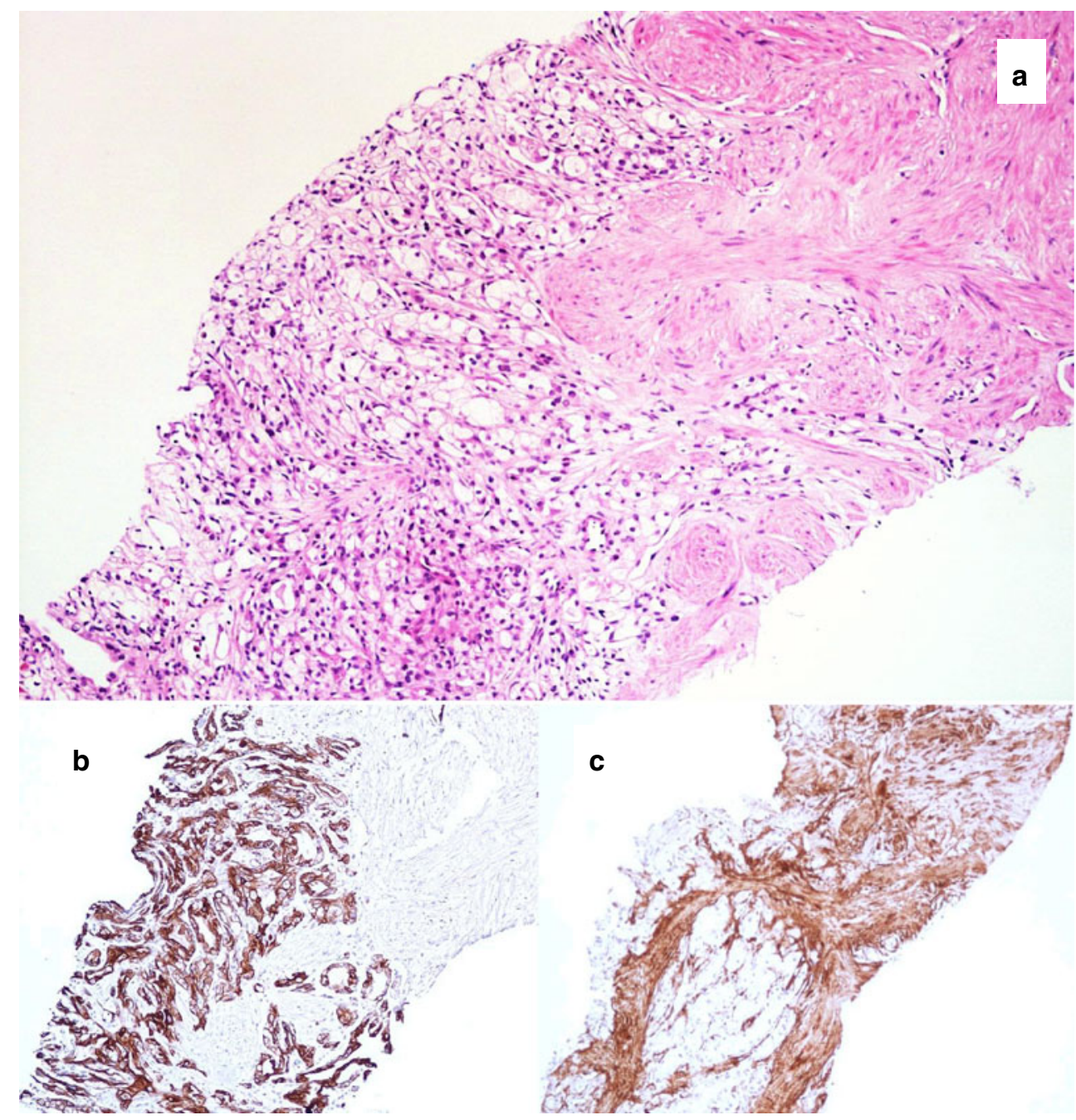


Fig. 3 Xanthogranulomatous pyelonephritis with pseudoglandular architecture of the foamy histiocytic infiltrate (a, hematoxylin and eosin, original magnification $\times 20$ ). Negativity of the pan-keratine AE1/AE3 (b, immunoperoxidase, $\times 20)$ and expression of CD68 (c, immunoperoxidase, $\times 20)$

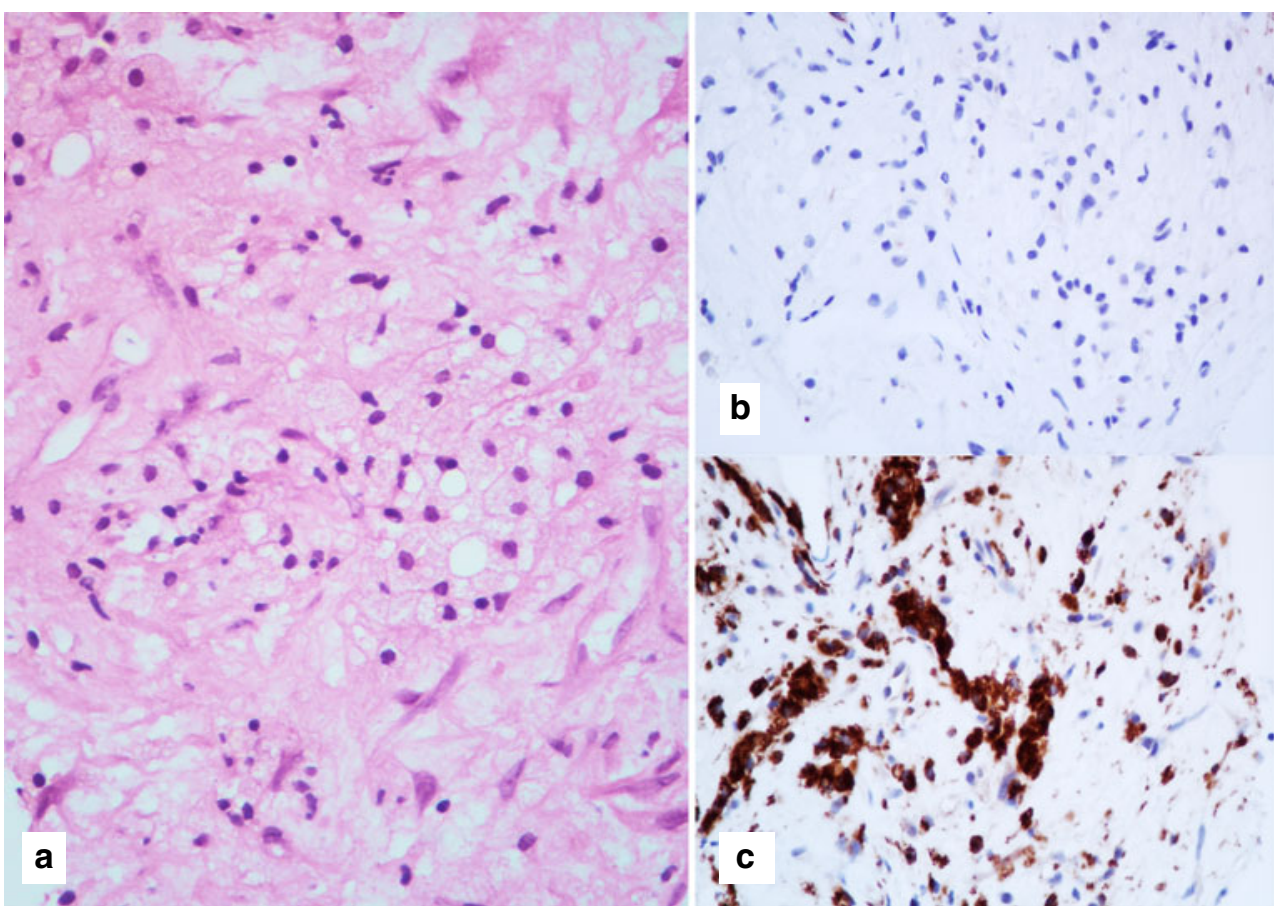

Eosinophilic cell tumors

\section{Chromophobe cell carcinoma and oncocytoma}

Chromophobe renal cell carcinoma and oncocytoma account for the majority of eosinophilic renal cell tumors. The distinction is clinically of paramount importance, given distinct managerial consequences. The differential diagnosis which may be difficult due to overlap in morphological features is greatly aided by the use of ancillary techniques.

Chromophobe RCC (Fig. 4a-d) is composed of clear, eosinophilic, or an admixture of clear and eosinophilic territories. Compared to the classical clear cell variant, in the eosinophilic variant, the cells are generally smaller, with regular and small nuclei, sometimes binucleated, often with a perinuclear halo. The stroma can be focally abundant and fibroedematous. Oncocytomas (Fig. 4e-h) are composed of cells with abundant eosinophilic cytoplasm without sharp delineation of the cell borders. The nuclei are round or with smooth contours and may show atypias, in the form of large irregular hyperchromatic bizarre nuclei. Another characteristic feature of the oncocytoma is the presence of a focally abundant fibroedematous stroma, but this finding is not specific [28].

The expression of CK7 (Fig. 4c, g) is the most discriminant available marker for the differential diagnosis (Table 4), usually intense and diffuse in chromophobe renal cell carcinoma while negative or very focal-in single cells or small clusters of cells - in $95 \%$ of oncocytomas. However, up to $20 \%$ of chromophobe carcinomas lack CK7 expression; hence, negativity of $\mathrm{CK} 7$ does not exclude this diagnosis.
CD117 (Fig. 4d, h) is another useful marker showing a diffuse cytoplasmic expression with peripheral accentuation in chromophobe renal cell carcinoma while being more often only focally expressed in oncocytoma (essentially in the cytoplasm without membrane reinforcement) $[29,30]$. CD10 and AMACR are usually negative in both entities, and expression of vimentin is variable, negative in chromophobe RCC, and possibly focally positive in a large proportion of oncocytomas [31]. CA-IX can be positive in perinecrotic areas of a chromophobe RCC and is consistently negative in oncocytoma. Hale's colloidal iron staining, traditionally recommended as a marker for chromophobe carcinoma, is now obsolete because of technical and interpretation issues.

Clinicians may be doubtful when a diagnosis of oncocytoma is rendered on a biopsy because of the possibility of a hybrid oncocytic/chromophobe tumor of which the potentially malignant component would not have been sampled. However, except in Birt-Hogg-Dubé syndrome or in the setting of renal oncocytomatosis, hybrid tumors appear exceedingly rare, less than $2 \%$ of oncocytoma and chromophobe RCC and do not justify a surgical management for all oncocytoma diagnosed on needles. Moreover, the behavior of these mixed neoplasms seems to be indolent [32].

\section{Differential diagnosis}

Other renal cell neoplasms less commonly presenting as eosinophilic cell lesions include a subset of CCRCC (discussed above) and papillary renal cell carcinomas (type II and oncocytic) which may comprise solid areas mimicking oncocytoma [33, 34]. In our institution, when dealing with 

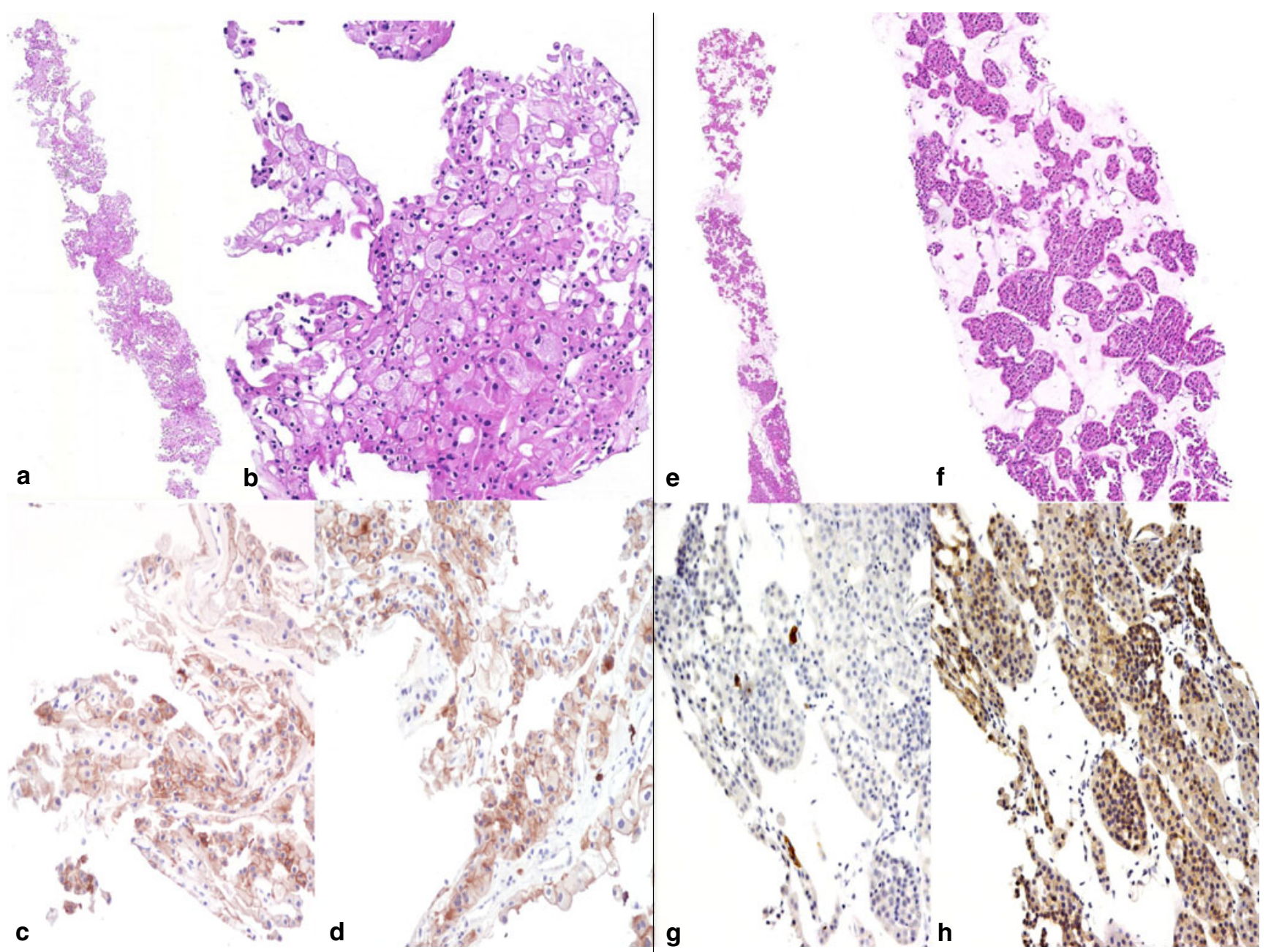

Fig. 4 Chromophobe RCC, mixed clear cell, and eosinophilic type (ad). The tumor is composed of large cells with abundant cytoplasm, sharp delineation of the cell borders, and wrinkled nuclei or perinuclear halo. (a, b, hematoxylin and eosin, original magnification $\times 2$ and $\times 10$ ). Diffuse expression of CK7 (c, immunoperoxidase $\times 20)$ and diffuse and intense membranous and cytoplasmic expression of CD117 (d,

small specimen, eosinophilic cell tumors are systematically immunostained for vimentin, CD10, AMACR, CD117, and CK7 (Table 4). In addition, PS100 may be added to the panel as the possibility of metastatic melanoma should also always be borne in mind. If angiomyolipoma is suspected, expression of actin, desmin, HMB45, and Melan-A is also assessed. Exceptional examples of sarcomatoid carcinoma immunoperoxidase $\times 20$ ). Oncocytoma $(\mathbf{e}-\mathbf{h})$. Core biopsy comprising nests of eosinophilic cells with regular nuclei disposed in an abundant fibroedematous stroma (e, f, hematoxylin and eosin, original magnifications $\times 2$ and $\times 20$ ). Positivity of isolated or small cluster of cells for CK7 (g, immunoperoxidase $\times 20$ ). Cytoplasmic expression of CD117 without membranous enhancement $(\mathbf{h}$, immunoperoxidase $\times 20)$

may exhibit rhabdoid features and present as an eosinophilic cell tumor (Fig. 5).

\section{Papillary tumors}

A variety of primary renal neoplasms or metastases may show a focal or extensive papillary pattern (Table 5). Once
Table 4 Immunohistochemistry for the differential diagnosis renal tumors with eosinophilic cells

\begin{tabular}{lllllll}
\hline & Vim & CK7 & CA-IX & CD10 & AMACR & CD117 \\
\hline Chromophobe RCC & - & ++ or - & - & $-/+$ & - & ++ \\
Oncocytoma & $-/+$ or - & - or $-/+$ & - & $-/+$ & - & $+/-$ \\
Clear cell RCC & ++ & $-/+$ & ++ & ++ & $+/-$ or - & - \\
Papillary type II RCC & ++ & + or $+/-$ & - & + & ++ & - \\
Papillary oncocytic RCC & ++ & + or $+/-$ & - & ND & ++ & - \\
\hline
\end{tabular}




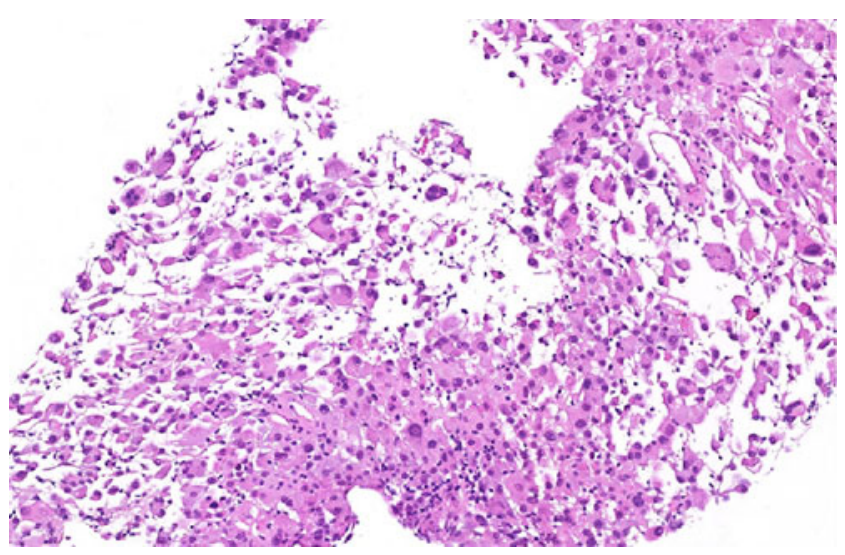

Fig. 5 Rhabdoid RCC. Sarcomatoid component presenting as rhabdoid tumor (hematoxylin and eosin $\times 20$ ). Expression of CK and INI1 (not shown)

papillary pattern is recognized, morphological analysis should assess the cytoplasmic features (eosinophilic, basophilic, or clear cell), the nuclear grade, the number of layer of cells lining the papilla, and the presence of foamy histiocytes (Fig. 6). In case of a carcinoma featuring a papillary architecture, immunohistochemistry may suggest the renal cell derivation by the positivity of AMACR and CK7. Vimentin and $\mathrm{CD} 10$ are generally at least focally positive. If these markers are lacking, metastatic, urothelial, or collecting duct carcinoma should be considered (discussed later). Even in the absence of a clear papillary architecture, the presence of foamy histiocytes is suggestive for papillary RCC. This diagnosis should also be entertained when dealing with an eosinophilic cell lesion, even of solid architecture (see above). Metanephric adenoma, a rare benign entity, must also be considered in the differential diagnosis of papillary neoplasms.

\section{Papillary renal cell carcinoma}

Papillary RCC comprises type I, type II, and the oncocytic variant. It is of interest to determine the subgroup of the papillary carcinoma because their prognoses are different. The type I and oncocytic variants are considered low-grade malignant neoplasm while type II is overall more aggressive with a prognosis similar to or worse than that of a clear cell RCC.

Papillary carcinoma, type I This entity features a typical and homogeneous morphology characterized by a delicate papillary architecture lined by a single layer of basophilic cells, with low nuclear grade (Fuhrman 1 or 2). Accumulation of foamy histiocytes in the vascular cores is virtually constant. Necrosis and cholesterol clefts may be abundant. AMACR, CK7, vimentin, and CD10 are almost always expressed (Table 4). Some tumors show a prominent tubular architecture with only minimal papillary pattern, which may be the only component sampled on biopsy. The presence of foamy macrophages is helpful to distinguish this tumor type from the others of tubular architecture (Fig. 7).

Papillary carcinoma, type II Papillary carcinoma type II is a heterogeneous group of tumors with respect to their morphology, immunophenotype, molecular features, and prognosis. Expression of CK7 is not as systematic as in type I but AMACR is usually expressed. In general, the papillae are lined by one or several layers of eosinophilic cells. Fuhrman nuclear grade is higher than in type I (generally 3 or 4), and macrophages are less numerous. Necrosis and cholesterol deposits are frequent.

Oncocytic papillary renal cell carcinoma Oncocytic papillary renal cell carcinoma, formerly included in the group of type II carcinomas, was recently individualized because of its more indolent behavior. It consists of a proliferation of oncocytic cell with round nuclei and large nucleoli. At variance with papillary carcinoma type II, the papillae are mostly lined by a single layer of tumor cells. Foamy macrophages are more frequent than in papillary type II RCC. In all, the oncocytic type of papillary RCC is best described as a tumor resembling papillary type I with oncocytic cells [33].

Microphthalmia-associated transcription factor familyTFE3 translocation-associated renal carcinomas Translocation renal cell carcinoma comprises a group of neoplasms characterized by translocation involving genes encoding transcription factors of the microphthalmia-associated transcription factor family, TFE3, or less frequently TFEB, with various gene partners. The most frequent translocations

Table 5 Renal tumors with possibly focal or extensive papillary architecture

Renal tumors of papillary architecture

Papillary RCC type I and II, papillary oncocytic RCC

Translocation RCC

Clear cell papillary RCC

Hereditary leiomyomatosis and renal cell cancer syndrome related RCC

Other renal tumors possibly comprising a papillary component

Clear cell RCC

Collecting duct carcinoma

Metanephric adenoma

Mucinous tubular and spindle cell carcinoma

Urothelial carcinoma

Chromophobe RCC

Oncocytoma

Metastasis 


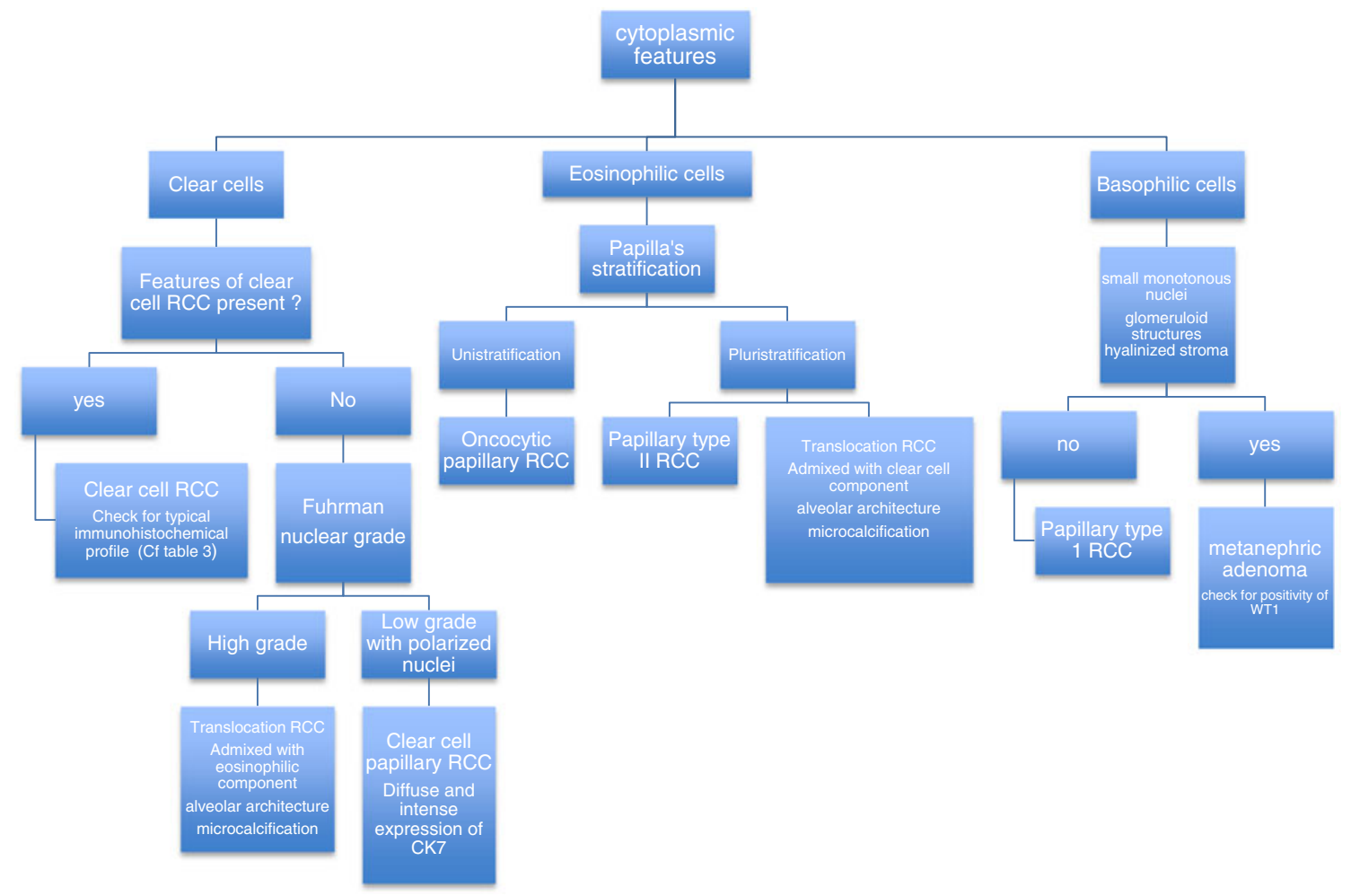

Fig. 6 Algorithm for assessment of papillary tumors on core renal biopsies (metastases are not listed but also enter in the differential diagnosis)

involve TFE3 with alveolar soft part sarcoma locus or papillary renal cell carcinoma. First described in pediatric population, translocation RCC also occurs in adults accounting for 1 to $4 \%$ of RCCs. Translocation RCC is often
Fig. 7 Papillary RCC probably of type I with prominent tubular architecture (a, hematoxylin and eosin $\times 4$ ). The presence of foamy histiocytes is a useful hint to the diagnosis ( $\mathbf{b}$, hematoxylin and eosin $\times 20$ ). The typical immunohistochemical profile includes diffuse and strong expression of AMACR

$(\mathbf{c}$, immunoperoxidase $\times 20)$ and expression of $\mathrm{CK} 7$, which was focal in this case

(d, immunoperoxidase $\times 20$ )
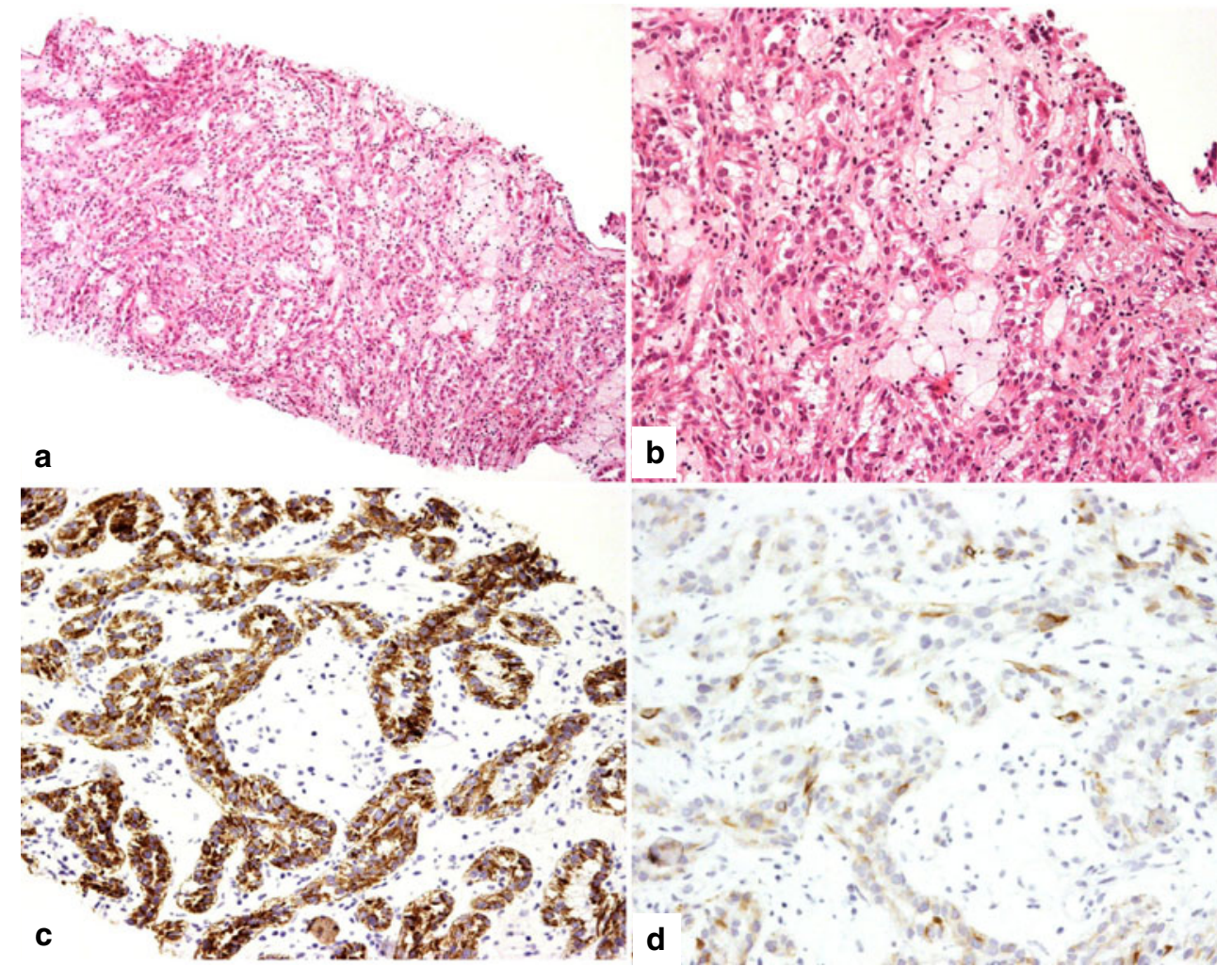
present with advanced disease and distant metastasis and carries a dismal prognosis.

Characteristic features of translocation carcinomas include the presence of a mixed alveolar/papillary architecture with an admixture of large clear and eosinophilic cells, the presence of calcifications, and high nuclear grade. Upon immunohistochemistry, translocation carcinomas are usually negative for keratin expression, and hence the diagnosis should always be entertained in front of a keratin-negative renal tumor. EMA can be focally positive, and there is a variable expression of vimentin, AMACR, Melan-A, and HMB45. The diagnosis is definitely proven by the demonstration of TFE3 or TFEB expression [26] and/or by evidencing the gene rearrangement by FISH assay [35].

Metanephric adenoma Metanephric adenoma is a rare benign neoplasm composed of small primitive cells resembling early metanephric tubular differentiation. Histologic features encompass small acini, papillary, and glomeruloid structures composed of monotonous cells with small nuclei and minimal blue cytoplasm. The stroma is often hyalinized and may be abundant. Mitoses are rare or absent. The papillary component may resemble type 1 papillary RCC but the nuclei are smaller, the cytoplasm is less abundant, and CK7 is usually less diffusely positive than in papillary carcinoma type 1 . AMACR is positive in both entities. WT1 is helpful, showing often diffuse nuclear positivity in metanephric adenoma [36].

Tumors comprising a spindle cell component

\section{High-grade spindle cell component}

When facing a cytologically high-grade spindle cell component, the first diagnosis to consider is a sarcomatoid carcinoma. The probability of finding a sarcomatoid component in small renal masses is low and increases with the tumor size. The identification of sarcomatoid carcinoma is often supported by the presence of an admixed cytologically high-grade epithelial component. In case of proliferations composed exclusively of spindle cells, immunohistochemistry for demonstration of keratin and/or EMA expression is usually useful.

A large variety of primary or secondary sarcomas may involve the kidney. One of the most frequently encountered is synovial sarcoma. Kidney synovial sarcoma is a highly cellular tumor in which tumor cells form short, intersecting fascicles dissecting the native renal parenchyma. This spindle cell solid component is often admixed with cysts of different size lined by hobnail cells. EMA and cytokeratins can be focally positive in the spindle cells and in the cells lining the cyst. The diagnosis is definitely established by the demonstration of SYT-SSX fusion at the genetic level or demonstration of the fusion transcript by molecular studies [37].
Low-grade spindle cell lesions

Angiomyolipoma is the most common primary renal tumor with a low-grade spindle cell component. Expression of HMB45 and Melan-A in addition to smooth muscle actin and desmin is characteristic. Other entities in the differential diagnosis include clear cell carcinoma with leiomyomatous stroma (discussed above) and mucinous tubular and spindle cell carcinoma. The latter consists of low-grade epithelial cells in the form of elongated tubules and spindle cells, separated by variable amounts of mucinous stroma. CK7 and AMACR are usually positive. CD10 is negative [38].

Tumors with an infiltrative pattern and desmoplasia

Desmoplasia is not a feature of most renal cell carcinomas, which tend to grow in a pushing manner. An infiltrative pattern of growth between residual glomeruli or tubules brings up the differential diagnoses of collecting duct carcinoma, the very rare renal medullary carcinoma, urothelial carcinoma, and metastasis. In this setting, PAX2 and PAX8 transcription factors represent two potentially useful markers for the demonstration of renal cell derivation.

\section{Collecting duct carcinoma and renal medullary carcinoma}

Collecting duct carcinoma is extremely rare (less than $1 \%$ of renal malignancies). It comprises a tubular or tubulopapillary infiltrative growth with a desmoplastic and often inflammatory stroma. Solid, cord-like features may be encountered. In case of prominent papillary architecture, papillary renal cell carcinoma may be suspected but the latter usually lacks desmoplasia.

Renal medullary carcinoma is a very rare entity occurring almost exclusively in young patients with sickled cell trait, viewed by some authors as an aggressive form of collecting duct carcinoma. Intratumoral inflammatory infiltrates, mostly neutrophils, are a constant finding and sickle red blood cell may be recognized. Recent data suggest consistent loss of INI-1 expression in these tumors [39].

\section{Urothelial carcinoma}

Invasive urothelial carcinoma in the kidney usually manifests as high-grade carcinoma, poorly differentiated, or with glandular differentiation. Immunohistochemistry is helpful to demonstrate the expression of CK7, CK20, CK5/6, and $\mathrm{p} 63$. The latter is very useful for distinguishing from collecting duct carcinoma [40]. Conversely, urothelial carcinoma lacks CD10 and other renal cell markers [30] (Fig. 8). 
Fig. 8 Invasive high-grade urothelial carcinoma (a, hematoxylin and eosin $\times 2$ ). This field illustrates nests of atypical cells, desmoplastic fibrous stroma, and residual atrophic renal tubules $(\mathbf{b}$, hematoxylin and eosin $\times 10$ ). Immunohistochemical profile includes nuclear expression of $\mathrm{P} 63$

(c, immunoperoxidase $\times 10$ )

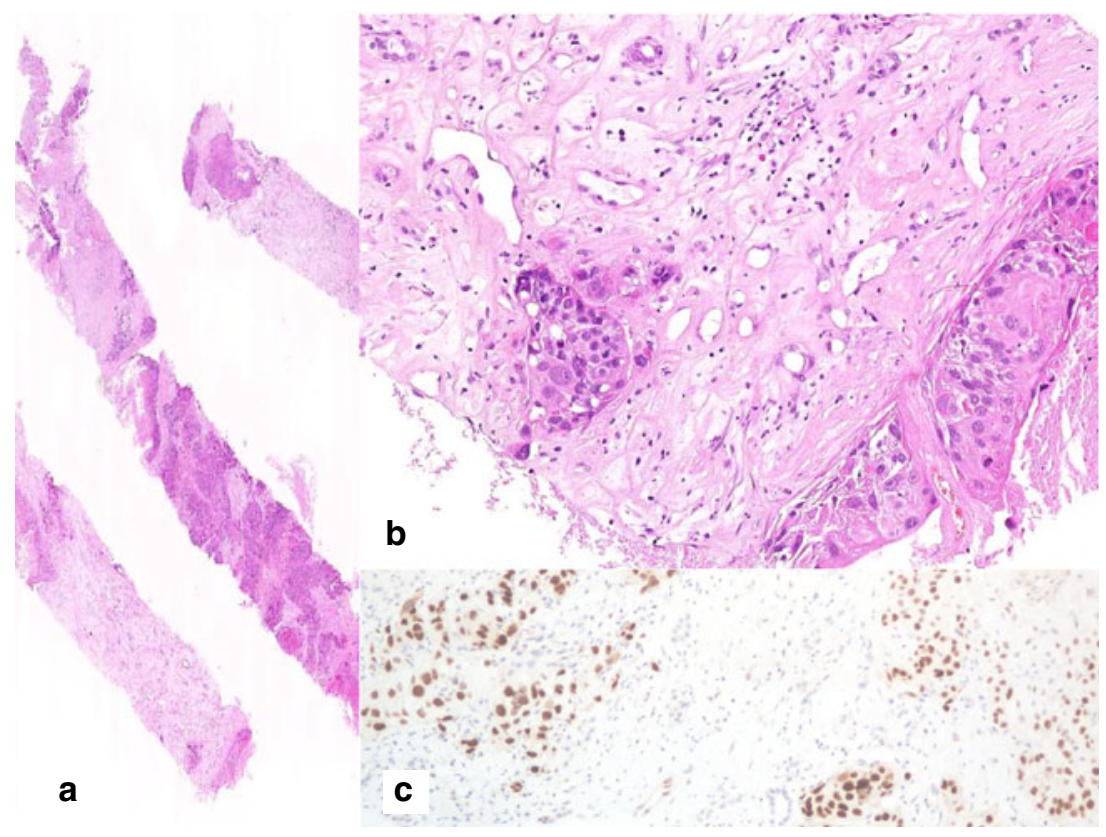

\section{Metastatic carcinoma}

The possibility of metastasis should be considered whenever a renal neoplasm appears unclassifiable as a primary lesion, i.e., any lesion not showing the classical morphologic features of a renal carcinoma (glandular architecture, desmoplasia, absence of clear cell, etc.) and immunohistochemical expression of classic renal markers (Table 6). It is of importance to stress that AMACR has no specificity for renal primaries and it is expressed in many adenocarcinomas of other origins, for example prostatic, gastric, or colorectal $[41,42]$. The most common primary sites are lung, breast, skin

Table 6 Commonly used markers for diagnostic immunohistochemistry: expression in normal kidney and in primary renal and extrarenal tumors

\begin{tabular}{|c|c|c|c|}
\hline & Normal kidney & Primary renal tumors & Extrarenal tumors \\
\hline Vimentin & Vessels & $\begin{array}{l}\text { Clear cell RCC } \\
\text { Papillary RCC }\end{array}$ & $\begin{array}{l}\text { Carcinoma of endometrium, thyroid, } \\
\text { and adrenal cortex }\end{array}$ \\
\hline Pan-CK & Tubules and glomeruli & $\begin{array}{l}\text { All types of RCC except } \\
\text { translocation carcinoma }\end{array}$ & Carcinoma \\
\hline CK7 & Tubules and glomeruli & $\begin{array}{l}\text { Papillary RCC } \\
\text { Chromophobe RCC } \\
\text { Leiomyomatous RCC } \\
\text { Clear Cell papillary RCC may } \\
\text { be focal in clear cell RCC }\end{array}$ & Variety of (adeno)carcinoma (breast, lung...) \\
\hline AMACR & $\begin{array}{l}\text { Epithelial cells of the } \\
\text { renal tubules }\end{array}$ & $\begin{array}{l}\text { Papillary RCC } \\
\text { Clear cell and translocation RCC }\end{array}$ & $\begin{array}{l}\text { Prostate, lung, colon, stomach, ovary, breast, } \\
\text { endometrium, gallbladder, neuroendocrine carcinomas }\end{array}$ \\
\hline CA IX & Not expressed & $\begin{array}{l}\text { Clear cell RCC } \\
\text { Collecting duct carcinoma }\end{array}$ & $\begin{array}{l}\text { Endometrium, stomach, cervix, breast, lung, liver, brain } \\
\text { tumors, neuroendocrine carcinomas, mesothelioma }\end{array}$ \\
\hline CD10 & $\begin{array}{l}\text { Podocytes, proximal tubular } \\
\text { cell brush borders }\end{array}$ & $\begin{array}{l}\text { Typical in clear cell, papillary, and } \\
\text { translocation RCC; can be expressed } \\
\text { in other renal epithelial neoplasm }\end{array}$ & $\begin{array}{l}\text { Various neoplasms of epithelial, stromal, or } \\
\text { hematopoietic derivation }\end{array}$ \\
\hline CD117 & ND & $\begin{array}{l}\text { Chromophobe RCC } \\
\text { Oncocytoma }\end{array}$ & Gastrointestinal stromal tumor, seminoma \\
\hline $\begin{array}{l}\text { PAX2 and } \\
\text { PAX8 }\end{array}$ & $\begin{array}{l}\text { Podocytes } \\
\text { Distal tubular cells } \\
\text { Lymphoid cells }\end{array}$ & $\begin{array}{l}\text { All types of primary RCC, decreased } \\
\text { in high grade, negative in } \\
\text { sarcomatoid carcinoma }\end{array}$ & $\begin{array}{l}\text { Lymphoma, nephrogenic adenoma, thyroid follicular } \\
\text { cell neoplasm }\end{array}$ \\
\hline RCC & $\begin{array}{l}\text { Proximal tubular } \\
\text { cell brush borders }\end{array}$ & $\begin{array}{l}\text { Clear cell RCC } \\
\text { Papillary RCC }\end{array}$ & $\begin{array}{l}\text { Adrenocortical tumors, breast and colon } \\
\text { carcinoma, embryonal carcinoma, parathyroid tumors, }\end{array}$ \\
\hline
\end{tabular}


Fig. 9 Epithelioid

angiomyolipoma. Proliferation of plump and spindle clear cells arranged in fascicle $(\mathbf{a}$,

hematoxylin and eosin $\times 20$ and

b, hematoxylin and eosin $\times 40$ ).

Immunohistochemical profile

includes intense expression of actin (c, immunoperoxidase $\times 20)$ and partial expression of Melan-A (d, immunoperoxidase $\times 20$ )
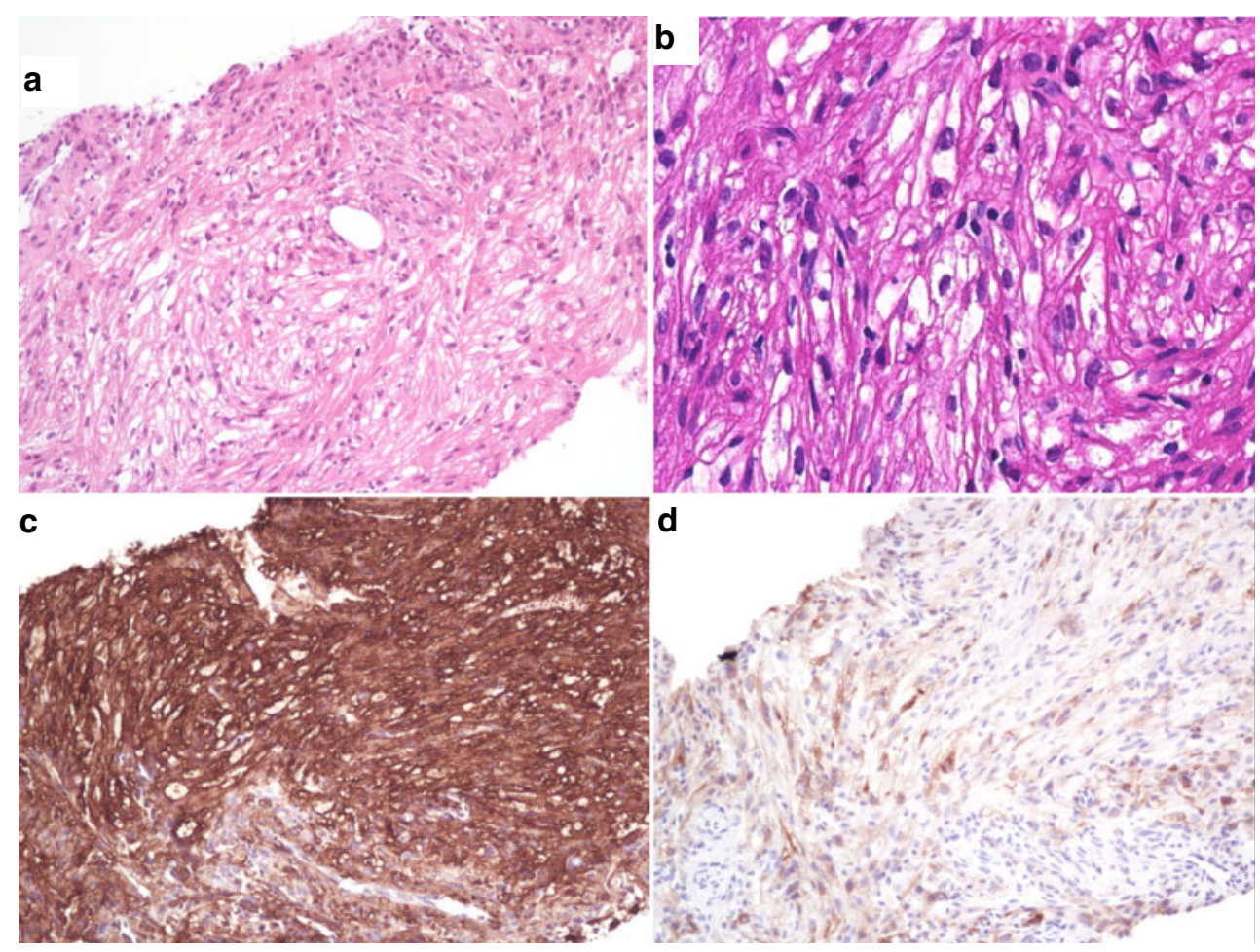

(malignant melanoma), contralateral kidney, gastrointestinal tract, ovary, and testis [43]. Renal metastases appear commonly in the late stages of evolution whereas renal metastasis as the initial manifestation of the primary is highly unusual.

\section{Angiomyolipoma}

Angiomyolipoma is a benign neoplasm that belongs to the perivascular epithelioid cell (PEC)-oma family of tumors. Its classical triphasic pattern associating variable amounts of adipose tissue, spindle or epithelioid smooth muscle cells, and abnormal thick-walled blood vessels is usually easily recognized histologically and often largely suspected radiologically because of the presence of adipose tissue. When the triphasic pattern is well represented, ancillary techniques are not necessary, but in case of diagnostic doubt, the immunohistochemical pattern is characteristic, with the epithelioid or spindle cells expressing muscular marker (alpha-actin and less frequently desmin) and some melanocytic markers as HMB45 and Melan-A [44]. PEComas are benign, and a simple surveillance can be recommended if the lesion is asymptomatic and small. Large tumors have to be removed because of the rare but real hemorrhagic risk.

Epithelioid angiomyolipoma of the kidney is a rare disease, closely related to classic, triphasic angiomyolipoma and considered as a potentially malignant neoplasm [45]. The epithelioid component is composed of large globulous or plump spindle cells with clear or eosinophilic cytoplasm and voluminous nuclei, similar to those of soft tissue
PEComas (Fig. 9). Epithelioid angiomyolipoma can be confused with clear cell RCC or with melanoma, but negativity of cytokeratin and PS100 and positivity of smooth muscle markers (actin and desmin) and HMB45 and/or Melan-A are diagnostic. The minimal amount of epithelioid component required to define angiomyolipoma as epithelioid, and so to suspect the lesion as potentially malignant, however, is not well defined. In our practice, epithelioid features in angiomyolipomas, when present, are systematically mentioned in the pathology report with a note suggesting that surgical removal would be performed.

\section{The nondiagnostic biopsy}

\section{Normal renal tissue and fibrous or fibroinflammatory tissue}

The proportion of biopsies composed of normal renal tissue or sampling only fibrous or fibroinflammatory tissue varies between 5 and $10 \%$ in published series. Importantly, a diagnosis of malignancy is eventually rendered in more than half of the patients who undergo nephrectomy or repeat biopsies, advocating the need for a second biopsy in case of a nonconclusive biopsy [21]. A final diagnosis of scar or pyelonephritis should strictly correlate with clinical and radiological settings.

\section{Necrotic tissue}

Although biopsies are performed under imaging guidance in order to be directed to viable areas, in rare cases, biopsies 
may exclusively sample necrotic tissue, raising the differential diagnosis of the underlying process as neoplastic versus inflammatory. Immunohistochemistry can be helpful, as the immunoreactivity of carcinomatous cells for CK or EMA is usually conserved, even when necrotic.

\section{Concluding remarks}

A good morphological analysis in conjunction with the appropriate use of an immunohistochemical panel can lead to a precise diagnosis for a vast majority of the renal masses sampled by core biopsy. This is now of importance because of the need of pretherapeutic diagnosis in an increasing number of situations. Nevertheless, definitive tumor typing is not always possible, for example in the case of cytologically low-grade neoplasms with clear cell features or in the case of eosinophilic cell proliferations. In those situations, it is important to state whether the renal cell origin of the lesion can be confirmed and to mention the nuclear grade. Deferring the definitive diagnosis to the examination of the surgical material appears as a reasonable option without impending appropriate management of the patient.

Cytogenetic studies, like FISH or comparative genomic hybridization ( $\mathrm{CGH}$ ) array, can determine changes known to be specifically or preferentially associated with each tumor type. For example, deletion of $3 p$ is characteristic of CCRCC, hyperploidy is characteristic for papillary RCC, and hypoploidy for chromophobe RCC. This kind of ancillary techniques is currently not routinely performed, with the exception of TFE3 break-apart FISH assays for the identification of translocation RCC. Nevertheless, FISH and CGH array have been proven to be feasible on biopsy samples and could be considered as an option in the future to improve the accuracy of biopsy diagnosis $[46,47]$.

Acknowledgments The authors thank Prof. L. Guillou and Dr. V. Lindner for critically reading the article and Dr. L. Dix and Dr. A. Nobile for the technical support.

Conflict of interest We declare that we have no conflict of interest.

\section{References}

1. Ljungberg B, Cowan NC, Hanbury DC et al (2010) EAU guidelines on renal cell carcinoma: the 2010 update. Eur Urol 58 (3):398-406

2. Leveridge MJ, Finelli A, Kachura JR et al (2011) Outcomes of small renal mass needle core biopsy, nondiagnostic percutaneous biopsy, and the role of repeat biopsy. Eur Urol 60(3):578-584

3. Jayson M, Sanders H (1998) Increased incidence of serendipitously discovered renal cell carcinoma. Urology 51(2):203-205

4. Remzi M, Marberger M (2009) Renal tumor biopsies for evaluation of small renal tumors: why, in whom, and how? Eur Urol 55 (2):359-367
5. Shah RB, Bakshi N, Hafez KS et al (2005) Image-guided biopsy in the evaluation of renal mass lesions in contemporary urological practice: indications, adequacy, clinical impact, and limitations of the pathological diagnosis. Hum Pathol 36(12):1309-1315

6. Wang R, Wolf JS Jr, Wood DP Jr et al (2009) Accuracy of percutaneous core biopsy in management of small renal masses. Urology 73(3):586-590, discussion 590-1

7. Volpe A, Mattar K, Finelli A et al (2008) Contemporary results of percutaneous biopsy of 100 small renal masses: a single center experience. J Urol 180(6):2333-2337

8. Breen DJ, Railton NJ (2010) Minimally invasive treatment of small renal tumors: trends in renal cancer diagnosis and management. Cardiovasc Intervent Radiol 33(5):896-908

9. Boorjian SA, Uzzo RG (2009) The evolving management of small renal masses. Curr Oncol Rep 11(3):211-217

10. Laguna MP, Kümmerlin I, Rioja J et al (2009) Biopsy of a renal mass: where are we now? Curr Opin Urol 19(5):447-453

11. Bosniak MA (1986) The current radiological approach to renal cysts. Radiology 158(1):1-10

12. Neuzillet Y, Lechevallier E, Andre M et al (2004) Accuracy and clinical role of fine needle percutaneous biopsy with computerized tomography guidance of small (less than $4.0 \mathrm{~cm}$ ) renal masses. J Urol 171(5):1802-1805

13. Breda A, Treat EG, Haft-Candell L et al (2010) Comparison of accuracy of 14-, 18- and 20-G needles in ex-vivo renal mass biopsy: a prospective, blinded study. BJU 105(7):940-945

14. Ficarra V, Brunelli M, Novara G et al (2011) Accuracy of on-bench biopsies in the evaluation of the histological subtype, grade, and necrosis of renal tumours. Pathology 43(2):149-155

15. Al-Ahmadie HA, Alden D, Fine SW et al (2011) Role of immunohistochemistry in the evaluation of needle core biopsies in adult renal cortical tumors: an ex vivo study. Am J Surg Pathol 35 (7):949-961

16. Strojan Flezar M, Gutnik H, Jeruc J et al (2011) Typing of renal tumors by morphological and immunocytochemical evaluation of fine needle aspirates. Virchows Arch 459(6):607-614

17. Eble JN, Sauter G, Epstein JI et al (2004) World Health Organization classification of tumours, pathology and genetic of tumours of the urinary system and male genital organs. IARC Press, Lyon

18. Al-Ahmadie HA, Alden D, Qin LX et al (2008) Carbonic anhydrase IX expression in clear cell renal cell carcinoma: an immunohistochemical study comparing 2 antibodies. Am J Surg Pathol 32(3):377-382

19. Leppert JT, Lam JS, Pantuck AJ et al (2005) Carbonic anhydrase IX and the future of molecular markers in renal cell carcinoma. BJU Int 96(3):281-285

20. Zubac DP, Bostad L, Kihl B et al (2008) Organ-confined clear cell renal cell carcinoma: the prognostic impact of microvascular invasion, nuclear grade and tumour size. APMIS 116(12):1027-1033

21. Lebret T, Poulain JE, Molinie V et al (2007) Percutaneous core biopsy for renal masses: indications, accuracy and results. J Urol 178(4 Pt 1):1184-1188, discussion 1188

22. Reuter VE, Tickoo SK (2010) Differential diagnosis of renal tumours with clear cell histology. Pathology 42(4):374-383

23. Adam J, Couturier J, Molinie V et al (2011) Clear-cell papillary renal cell carcinoma: 24 cases of a distinct low-grade renal tumour and a comparative genomic hybridization array study of seven cases. Histopathology 58(7):1064-1071

24. Srigley JR, Delahunt B (2009) Uncommon and recently described renal carcinomas. Mod Pathol 22(Suppl 2):S2-S23

25. Kuhn E, De Anda J, Manoni S et al (2006) Renal cell carcinoma associated with prominent angioleiomyoma-like proliferation: report of 5 cases and review of the literature. Am J Surg Pathol 30 (11):1372-1381

26. Ross H, Argani P (2010) Xp11 translocation renal cell carcinoma. Pathology 42(4):369-373 
27. Sangoi AR, Fujiwara M, West RB et al (2011) Immunohistochemical distinction of primary adrenal cortical lesions from metastatic clear cell renal cell carcinoma: a study of 248 cases. Am J Surg Pathol 35(5):678-686

28. Amin MB, McKenney JK, Tickoo SK et al (2010) Diagnostic pathology. Genitourinary. Amirsys, Inc, Canada

29. Carvalho JC, Wasco MJ, Kunju LP et al (2011) Cluster analysis of immunohistochemical profiles delineates CK7, vimentin, S100A1 and C-kit (CD117) as an optimal panel in the differential diagnosis of renal oncocytoma from its mimics. Histopathology 58(2):169-179

30. Truong LD, Shen SS (2011) Immunohistochemical diagnosis of renal neoplasms. Arch Pathol Lab Med 135(1):92-109

31. Hes O, Michal M, Kuroda N et al (2007) Vimentin reactivity in renal oncocytoma: immunohistochemical study of 234 cases. Arch Pathol Lab Med 131(12):1782-1788

32. Petersson F, Gatalica Z, Grossmann P et al (2010) Sporadic hybrid oncocytic/chromophobe tumor of the kidney: a clinicopathologic, histomorphologic, immunohistochemical, ultrastructural, and molecular cytogenetic study of 14 cases. Virchows Arch 456(4):355365

33. Hes O, Brunelli M, Michal M et al (2006) Oncocytic papillary renal cell carcinoma: a clinicopathologic, immunohistochemical, ultrastructural, and interphase cytogenetic study of 12 cases. Ann Diagn Pathol 10(3):133-139

34. Mai KT, Kohler DM, Robertson SJ et al (2008) Oncocytic papillary renal cell carcinoma with solid architecture: mimic of renal oncocytoma. Pathol Int 58(3):164-168

35. Kim SH, Choi Y, Jeong HY et al (2011) Usefulness of a breakapart FISH assay in the diagnosis of Xp11.2 translocation renal cell carcinoma. Virchows Arch 459(3):299-306

36. Davis CJ Jr, Braton JH, Sesterhenn IA et al (1995) Metanephric adenoma. Clinicopathological study of fifty patients. Am J Surg Pathol 19(10):1101-1114

37. Argani P, Faria PA, Epstein JI et al (2000) Primary renal synovial sarcoma: molecular and morphologic delineation of an entity previously included among embryonal sarcomas of the kidney. Am J Surg Pathol 24(8):1087-1096

38. Ferlicot S, Allory Y, Comperat E et al (2005) Mucinous tubular and spindle cell carcinoma: a report of 15 cases and a review of the literature. Virchows Arch 447(6):978-983

39. Cheng JX, Tretiakova M, Gong C et al (2008) Renal medullary carcinoma: rhabdoid features and the absence of INI1 expression as markers of aggressive behavior. Mod Pathol 21(6):647-652

40. Kobayashi N, Matsuzaki O, Shirai S et al (2008) Collecting duct carcinoma of the kidney: an immunohistochemical evaluation of the use of antibodies for differential diagnosis. Hum Pathol 39 (9):1350-1359

41. Truong CD, Li W, Feng W et al (2008) Alpha-methylacyl-CoA racemase expression is upregulated in gastric adenocarcinoma: a study of 249 cases. Int J Clin Exp Pathol 1(6):518-523

42. Shi X, Gong E, Wu X (2007) Alpha-methylacyl-CoA racemase/ P504S overexpression in colorectal carcinoma is correlated with tumor differentiation. Appl Immunohistochem Mol Morphol 15 (2):175-180

43. Murphy WM et al (2004) AFIP Atlas of Tumor Pathology series 4, tumors of the kidney, bladder and related urinary structures. American Registry of Pathology, Washington DC

44. Martignoni G, Pea M, Reghellin D et al (2008) PEComas: the past, the present and the future. Virchows Arch 452(2):119-132

45. Faraji H, Nguyen BN, Mai KT (2009) Renal epithelioid angiomyolipoma: a study of six cases and a meta-analytic study. Development of criteria for screening the entity with prognostic significance. Histopathology 55(5):525-534

46. Barocas DA, Mathew S, delPizzo JJ et al (2007) Renal cell carcinoma sub-typing by histopathology and fluorescence in situ hybridization on a needle-biopsy specimen. BJU Int 99 (2):290-295

47. Vieira J et al (2010) Feasibility of differential diagnosis of kidney tumors by comparative genomic hybridization of fine needle aspiration biopsies. Genes Chromosomes Cancer 49(10):935-947 